\title{
PODERES LOCALES, MONARQUÍA Y PROPIEDAD COMUNAL EN LOS CONCEJOS DE REALENGO CASTELLANOS, BAJOMEDIEVALES
}

\author{
CORINA LuCHÍA
}

\begin{abstract}
Resumen: En este trabajo se indaga acerca de las diferentes estrategias que los poderes políticos desarrollan en torno de la cuestión de los términos comunales en los siglos bajomedievales en el ámbito concejil de realengo castellano. Tanto las oligarquías villanas como la propia monarquía elaboran diversas políticas que en una primera aproximación pueden resultar ambivalentes e incluso contradictorias. Desde la protección y defensa de estos campos colectivos, hasta su cerramiento y privatización, las diversas medidas forman parte de un entramado que sólo puede ser comprendido dentro de las determinaciones que imponen las relaciones sociales y económicas concretas que se establecen en cada concejo en particular, respondiendo al singular balance de fuerzas entre los poderes locales y el vértice superior del reino, expresado en el Soberano y los distintos órganos de gobierno real.
\end{abstract}

Palabras claves: Propiedad comunal-Oligarquías concejiles-Monarquía.

Abstract: In this work it is investigated brings over of the different strategies that the political power develop around the question of the communal terms in the midleages centuries in the area concejil of realengo Castilians. So much the oligarchies villanas as the own monarchy elaborate diverse policies that in the first approximation can turn out to be ambivalent and even contradictory. From the protection and defense of these collective fields, up to his closing and privatization, the diverse measures form a part of a studding that only can be understood inside the determinations that impose the social and economic concrete relations that are established in every council especially, answering to the singular balance of forces between the local power and the top vertex of the kingdom, expressed in the Sovereign one and the different organs of royal government.

Keywords: communal property-oligarchies-monarchy. 


\section{BREVES CONSIDERACIONES INICIALES}

La propiedad comunal ocupa un lugar central dentro de la organización socioproductiva de los concejos de realengo castellanos. Sin embargo su gravitación no se limita al aspecto estrictamente económico, como proveedores de recursos complementarios de las parcelas individuales. En tanto aseguran la reproducción material de los distintos sectores, constituyen ámbitos de disputa entre las fuerzas sociales dominantes y juegan dentro de la dinámica de construcción de poder en el nivel local del reino.

Por todo ello, los términos comunes son objeto de numerosas luchas dentro de la intensa conflictividad que atraviesa los siglos bajomedievales.

Entre los aportes que analizan los conflictos por los comunes, advertimos una lectura unilateral que reduce el proceso a la ofensiva privatizadora emprendida por los señores y las oligarquías villanas, frente a comunidades presentadas como débiles, sólo amparadas por la lejana intervención protectora de la monarquía. Esta interpretación está presente tanto en los abordajes materialistas, en sus versiones estructuralistas y genético estructurales ${ }^{1}$, como en los institucionales y jurídicos ${ }^{2}$. Sin subestimar la importancia de las acciones lesivas del patrimonio comunal que encabezan estos grupos del bloque de poder feudal, la persistencia de este tipo de bienes y la fortaleza de los colectivos campesinos que trasciende largamente el período recortado en este estudio, permiten matizar esta perspectiva generalizada y reconocer la capacidad de las comunidades no sólo para promover la defensa de sus intereses, sino para en muchos casos pasar a la ofensiva y enfrentar a caballeros y señores ${ }^{3}$.

1. Astarita, C., «Estudio sobre el concejo medieval de la Extremadura castellano-leonesa. Una propuesta para resolver su problemática», en Hispania, 1982; Idem, «Estructura social del Concejo primitivo de la Extremadura castellano-leonesa. Problemas y controversias», en Anales de Historia Antigua y Medieval, FFyL, UBA, Bs. As., 1993; PAStor, R., Resistencias y luchas campesinas en la época de crecimiento y consolidación de la formación feudal. Castilla y León, siglos X-XIII, Siglo XXI, Madrid, 1980; CARMONA RuIz, M. A. Usurpación de tierras y derechos comunales en Sevilla y su Tierra durante el siglo XV, Madrid, 1995; Monsalvo Antón, J. M., «Paisaje agrario, régimen de aprovechamientos y cambio de propiedad en una aldea de la tierra de Ávila durante el siglo Xv. La creación del término redondo de Zapardiel de Serrezuela», en Cuadernos Abulenses, 17, Ávila, enero-junio 1992; La Baja Edad Media en los siglos XIV-XV, Síntesis, 2000; idem «Usurpaciones de comunales: conflicto social y disputa legal en Ávila y su Tierra durante la Baja Edad Media», en Historia Agraria, n 24, agosto 2001.

2. VASSBERG, D., La venta de tierras baldías. El comunitarismo agrario y la Corona de Castilla durante el siglo XVI, Servicio de Publicaciones Agrarias, 1983; Idem, La venta de tierras baldias. El comunitarismo agrario y la Corona de Castilla durante el siglo XVI, Madrid, 1983; SÁnchez Albornoz, C., El régimen de la tierra en el reino asturleonés. Hace mil años., UBA, Bs. As., 1978; García De Valdeavellano, L., Historia de España. I. De los orígenes a la Baja Edad Media, Revista de Occidente, Madrid, 1973; Gómez MendozA, J., «La venta de baldíos y comunales en el siglo XVI. Estudio de su proceso en Guadalajara» en Estudios geográficos, 28, 1967; Beneyto Pérez, J., «Notas sobre el origen de los usos comunales», en Anuario de Historia del Derecho Español, tomo IX, Madrid, 1932.

3. Monsalvo Antón, J. M., «Percepciones de los pecheros medievales sobre usurpaciones de términos rurales y aprovechamientos comunitarios en los concejos salmantinos y abulenses», en Edad Media, 7, 2005-2006. 
Las oligarquías villanas que dominan los grandes concejos del área participan activamente en los procesos de ocupación y privatización masiva de tierras concejiles, pero sus acciones se inscriben dentro de una dinámica mayor de estructuración de relaciones de poder. Desde esta perspectiva los enfrentamientos por los campos comunales deben ser comprendidos dentro de un análisis de la conformación del poder feudal en el realengo, reconociendo las relaciones de las elites villanas con otras instancias de la dominación feudal, en particular el vínculo ambivalente que el estado monárquico establece con los grupos concejiles. En este sentido, la dualidad de las intervenciones tanto de los poderes locales, a través de los órganos concejiles, como del Rey, por medio de las disposiciones centrales y su ejecución en manos de los jueces específicos, expresa una compleja relación de competencia-cooperación tanto en el interior de los grupos villanos, como entre éstos y la monarquía.

En este entramado, los miembros de las oligarquías villanas, si bien cohesionados por las instituciones políticas respectivas de las cuales forman parte y en las que ocupan posiciones preeminentes, no actúan de manera uniforme ni armoniosa. Si bien entre las distintas familias que dominan el escenario concejil existen intereses coincidentes expresados en las mismas acciones privatizadoras sobre los campos abiertos, la propia dinámica del feudalismo bajomedieval lleva a estos grupos a desatar intensas rivalidades.

La necesidad que tiene el poder central de contar con el apoyo de las oligarquías para asegurar el trasvase del excedente campesino desde los concejos realengos hacia las arcas reales, y el objetivo de estos grupos de reforzar su posición dominante local por medio de la legitimación regia, no inhibe las relaciones altamente competitivas y contradictorias. Las transformaciones materiales de la estructura castellana así como los procesos de centralización creciente que promueve la realeza, refuerzan la tensión entre los intereses señorializadores de la elites villanas que terminan por disputar la jurisdicción regia sobre estos concejos y la potestad imperativa del soberano.

La diversidad de las políticas que la Corona implementa en cada concejo, así como las múltiples intervenciones de los grupos villanos, tornan imprescindible un análisis regionalizado. El estudio de caso permite reconstruir la conformación de redes de poder local estudiándolas en cada situación concreta, teniendo en cuenta el balance de fuerzas reales y las condiciones específicas que explican el carácter oscilante que aparentan tener las políticas sobre la propiedad comunal entre los siglos XIV y XV. Para ello centramos la indagación en los concejos de Ávila y Ciudad Rodrigo ${ }^{4}$, en los cuales se aprecia la intensidad del fenómeno en los numerosos pleitos desatados por la toma de tierras comunales.

4. Luis López, C. y Del Ser Quijano, G., (1990-1992), Documentación medieval del Asocio de la Extinguida Universidad y Tierra de Ávila, 2 tomos, Gran Duque de Alba, Ávila; Barrios García, A., Monsalvo Antón, 


\section{LOS APROVECHAMIENTOS COMUNALES EN LA ESTRUCTURA CONCEJIL DE REALENGO}

La propiedad comunal se encuentra atravesada por una intrincada trama de prácticas productivas ${ }^{5}$. Su definición trasciende el mero formalismo jurídico y se conforma a través de las acciones que los sujetos ejercen recurrentemente sobre el medio natural. La caza, la roza, el apacentamiento de ganado, la utilización de los cursos de agua, de los molinos y la obtención de leña, son los principales aprovechamientos abiertos de los términos comunitarios Si bien la principal riqueza de estos campos está dada por las vastas extensiones de suelos abiertos destinados a la pastura del ganado concejil, también proveen de otros recursos que complementan el producto de las parcelas individuales, como el combustible de bosques y turberas, los frutos silvestres o los cauces de aguas ${ }^{6}$. Mientras que estos últimos resultan de interés particular para la reproducción de los segmentos más débiles de las comunidades, los pastizales serán objeto de permanente apropiación por parte de los grandes propietarios de ganado locales y extracomunitarios que harán valer su peso económico, social y su poder coactivo, para garantizar su acceso privilegiado a ellos.

La reconstrucción de las redes de poder local de estos concejos demanda algunas precisiones previas acerca de su estructura social así como del carácter de sus grupos dominantes ${ }^{7}$. Mucho se ha debatido sobre la evolución de las orga-

J. M. y Del Ser Quijano, G., (1998), Documentación medieval del archivo municipal de Ciudad Rodrigo, Ed. De la Diputación de Salamanca, Salamanca.

5. Es en esta compleja estructura relacional que se configura la organización del espacio rural, cuya dinámica está determinada por condicionamientos materiales, iniciativas privadas y la acción del poder político, lo cual conforma en su totalidad la organización del terrazgo, Monsalvo AnTón, J. M., El sistema político concejil. El ejemplo del señorío medieval de Alba de Tormes y su concejo de Villa y Tierra, Salamanca, 1988. Con lo cual las prácticas productivas que atraviesan la existencia de los términos comunales se constituyen en el cruce de estos tres niveles.

6. Para una descripción detallada de los bienes comunales, véase MARTín, J. L., «Evolución de los bienes comunales en el siglo XV», en Studia Historica (Medieval), VIII, 1990.

7. La caracterización de las oligarquías villanas como segmentos locales de la nobleza feudal ha sido sostenida entre otros por Santamaría LANCho, M., «Del concejo y su término a la comunidad de ciudad y Tierra: surgimiento y transformación del señorío urbano de Segovia (s. XIII/XvI)», en Studia Histórica_(Medieval), V, 1985; Mínguez Fernández, J. M., Feudalismo y concejos. «Aproximación metodológica al análisis de las relaciones sociales en los concejos medievales castellano leoneses», En la España Medieval 3, 1982; BARRIos García, A., Estructuras agrarias y de poder en Castilla. El ejemplo de Ávila (1085-1320), Salamanca, 1983-84, 2 vol; Bonachía Hernando, J. A., «El concejo como señorío. (Castilla s. XIII-Xv)», en Concejos y ciudades en la Edad Media Hispánica, II Congreso de Estudios Medievales, Fundación Sánchez Albornoz, Móstoles, 1990. Por su parte la visión de estos grupos de caballeros villanos como una variante del campesinado independiente aunque funcional a la reproducción de la lógica feudal es defendida por PAstor, R., «En los comienzos de una economía deformada: Castilla», en Desarrollo Económico, 36, 1970; LóPEZ Rodríguez, C., «La organización del espacio rural en los fueros de la Extremadura castellana» en En la España medieval, 12, 1989; AstaRita. C., «Estudio sobre el concejo...», op. cit., «Caracterización económica 
nizaciones municipales, desde su conformación abierta y «democrática» en un área de frontera bajo la amenaza musulmana, hasta su cierre y aristocratización con la promoción del grupo de guerreros a la condición de clase dirigente que monopoliza el aparato de gobierno local en desmedro de la masa de campesinos tributarios $^{8}$. Si bien la presencia de grupos mercantiles y financieros complejiza la composición de las aristocracias urbanas 9 , la orientación económica predominante de estos grupos es la ganadera, orientación que les servirá de base de acumulación para su promoción como elites en el proceso de segregación social que experimentan los concejos desde finales del siglo XIII ${ }^{10}$.

La decadencia de los concejos «abiertos» $\mathrm{y}$ «democráticos» es paralela a la conversión de los caballeros en «clase de poder» en sentido estricto. En tanto se consolidan como clase propietaria exenta de obligaciones tributarias ${ }^{11}$, se promueven y estabilizan como clase dirigente local ejerciendo el control del aparato institucional del concejo ${ }^{12}$. Aquí se advierte una evolución del poder primitivo ligado al desempeño de una función estratégica para la reproducción social hacia formas de explotación desarrolladas ${ }^{13}$. La transformación de los concejos originarios en órganos fuertemente jerarquizados constituye una manifestación de dicho proceso. La aristocracia militar se afirma como aristocracia política, basando su poder en el ejercicio del mando, en el control de los mecanismos detractivos del plustrabajo campesino y en su posición como propietarios ganaderos ${ }^{14}$.

de los caballeros villanos de la Extremadura castellano- leonesa (siglos XII-Xv), en Anales de Historia Antigua y Medieval, 27, 1994, más recientemente «Los caballeros villanos», en Del feudalismo al capitalismo. Cambio social y político en Castilla y Europa occidental, 1250-1520, Univ. Granada/Valencia, 2005. Para el caso de Portugal, Martín, J. L., «Notas sobre las publicaciones medievales portuguesas», Studia Historica (medieval), IV, 1986.

8. Véase entre otros, Astarita, C., «Estudio sobre el concejo medieval...», op. cit., Idem, «Caracterización económica...», op. cit.; Monsalvo Antón, J. M., «Transformaciones sociales y relaciones de poder en los concejos de frontera, siglos XI-XIII. Aldeanos, vecinos y caballeros ante las instituciones municipales» en PAStOR, R. (Comp.) Relaciones de poder, de producción y parentesco en la Edad Media y Moderna, CSIC, 1990, Idem, el sistema político concejil...», op. cit.; SANTAMARÍA LANCHO, M., «Del concejo y su término a la comunidad de ciudad y Tierra: surgimiento y transformación del señorío urbano de Segovia (s. XIII/XVI)», en Studia Histórica_(Medieval), V, 1985, así como las diferentes contribuciones incluidas en Concejos y ciudades en la Edad Media, op. cit.;

9. Véase el planteo de VAldeón, J., «Las oligarquías urbanas», en II Congreso de Estudios Medievales..., op. cit. 10. Astarita, C., «Estudios sobre el concejo...», op. cit.

11. Idem.

12. Barrios García, C., Estructuras agrarias y de poder, op. cit.

13. Engels, F, Antidühring, Ed. Cartago, Bs. As., 1975.

14. En este punto coinciden desde diversos abordajes Astarita, C., «Estudios sobre el concejo...», op. cit., 1982, Barrios García, C., Estructuras agrarias y de poder..., op. cit.; Monsalvo Antón, J. M., «Transformaciones sociales...», op. cit. 
Los caballeros villanos que ejercen una función clave en la estructura de dominación feudal como agentes articuladores de la misma ${ }^{15}$, tienen una significativa incidencia en el amplio movimiento de usurpación de tierras que se observa a lo largo de la Baja Edad Media. Estos grupos económicamente poderosos y socialmente predominantes ya a mediados del XIII, que confirman su condición hegemónica en la estructura concejil en la siguiente centuria cuando su poder cristaliza en instituciones que les garantizan el monopolio de las decisiones políticas en el nivel local del reino, con la consiguiente subordinación de las aldeas a los concejos cabecera. A la preeminencia patrimonial y al prestigio social se le sumará entonces el privilegio político.

La institucionalización del Regimiento a mediados del siglo XIV, rubrica institucionalmente un desarrollo social previo que marca el triunfo de los sectores más poderosos dentro de la elite urbana y el desplazamiento hacia posiciones marginales y secundarias de los más modestos ${ }^{16}$. No obstante, si bien la caballería ejerce sobre los concejos aldeanos y sus pecheros un señorío colectivo, las atribuciones estrictamente señoriales le corresponden al señor de la villa, que en los casos estudiados se enmarcan en la jurisdicción regia, aspecto central éste en la regulación de los aprovechamientos comunes, que explica el papel que juega la Corona en la resolución de los conflictos.

Las oligarquías villanas aseguran la dominación feudal en el área ejerciendo la función fiscal sobre la Tierra. Sin embargo, el excedente que se extrae a las aldeas desde los concejos principales es apropiado de manera colectiva, y representa una parte mínima de las exacciones a las que son sometidos los pecheros ${ }^{17}$. Ello da cuenta de que la tributación directa constituye una forma secundaria de reproducción de las elites villanas ${ }^{18}$. La misma se basa en la explotación de la mano de obra campesina que sometida a procesos de pauperización, con la fragmentación de las parcelas y la pérdida de acceso a amplias superficies de suelos abiertos, se verá progresivamente obligada a entrar en vínculos de dependencia laboral con este sector de propietarios enriquecidos.

15. Astarita, C. «Caracterización económica...», op. cit.

16. En este sentido señala Monsalvo Antón, J. M., «...la regiduría, un bien escaso, no será algo instrumental para los grupos privilegiados, sino también un indicador, una marca, un atributo para la elite de la elite, para aquellos individuos o familias concretas que aun dentro de los que llamamos socialmente «oligarquía urbana», lograron alcanzar la preeminencia especial del patriciado urbano, entendido como categoría que aunaba de forma integral poder socioeconómico, prestigio y poder político», «La sociedad política en los concejos castellanos de la meseta durante la época del regimiento medieval. La distribución social del poder», en II Congreso de Estudios Medievales, op. cit., p. 363.

17. Como se ha comprobado para el caso de Alba de Tormes en el siglo XV la tributación directa sólo representa el diez por ciento de las exacciones, Monsalvo Antón, J.M., El sistema político concejil, op. cit.

18. Astarita, C., «Los caballeros villanos», op. cit. 
El paisaje socioeconómico de los concejos en la etapa estudiada se caracteriza por una masa de campesinos aldeanos económicamente frágiles que complementan los recursos obtenidos en sus parcelas individuales con el usufructo de los términos comunes. La debilidad material de estos segmentos aldeanos los obliga a emplearse como mano de obra de grandes propietarios villanos que han fortalecido su posición económica enraizada en la ganadería y las explotaciones integrales que reúnen producción pecuaria, cerealera, así como manufacturas rurales. Los grandes propietarios al avanzar sobre las tierras concejiles y depredar los usos comunitarios favorecen el proceso de descomposición de las comunidades del que se beneficiarán con la obtención de trabajadores asalariados. Sin embargo, las prácticas productivas y las normas consuetudinarias que caracterizan al campesinado medieval, obstaculizan este proceso, debiendo en muchos casos, apelar a los resortes políticos del aparato concejil que controlan para asegurar sus acciones y compeler a la venta del trabajo aldeano.

\section{REDES DE PODER Y ESTRATEGIAS DE LAS OLIGARQUÍAS VILLANAS: EL CASO DE ÁVILA Y CIUDAD RODRIGO}

La reconstrucción de las redes de poder locales, demanda realizar análisis de casos a partir de los cuales se pueden establecer comparaciones que permitan identificar tendencias regionales. En los numerosos litigios estudiados es posible reconocer las diferentes estrategias que los grandes propietarios villanos elaboran para consolidar su poder tanto a nivel material como político.

Si bien el poder y la supremacía a nivel local de las oligarquías villanas afecta los intereses materiales de los campesinos, la persistencia activa de los representantes pecheros, con el papel protagónico desempeñado a lo largo de los pleitos bajomedievales por los procuradores ${ }^{19}$, dan cuenta de la capacidad de los tributarios en tanto organización colectiva, para defender sus recursos e intervenir en el sistema político, aún estando excluidos de las instancias decisionales formales. Los procuradores pecheros apelan ante las instancias judiciales provistas por el realengo, manipulan con habilidad los argumentos jurídicos, construyen un discurso capaz de legitimar sus reclamos identificando sus intereses con los de la propia monarquía, y prosiguen pleitos prolongados pese a las dificultades que encuentran para obtener la ejecución de las resoluciones. De este modo, la decidida actuación de las comunidades pecheras en la preservación de sus términos abiertos, rechaza el tópico historiográfico de un supuesto monoli-

19. La actuación de Alfonso Sánchez del Tiemblo en el caso de Ávila es ilustrativa a lo largo de los numerosos litigios de la fortaleza y capacidad política de las comunidades, véase Asocio, Doc 70, 71, 74 y otros. 
tismo oligárquico en los concejos ${ }^{20}$, y da cuenta de su efectiva intervención en la dinámica política local ${ }^{21}$.

Sin embargo, la participación de los concejos de aldea en la lucha por su patrimonio común no es expresión de una comunidad homogénea que defiende un acceso igualitario y mancomunado a los suelos abiertos. Por el contrario, los colectivos que se involucran en estas luchas se encuentran atravesados también por procesos de transformación y diferenciación social. La utilización de campesinos pobres semidesposeidos como fuerza de trabajo y a la vez como agentes de la privatización de los términos por parte de los caballeros y señores es expresión de las transformaciones estructurales que están socavando a las entidades comunitarias $^{22}$.

Por todo ello, la idea de una comunidad aldeana uniforme que se vuelca sin fisuras a la defensa decidida de la propiedad comunal frente a los abusos de los grupos villanos, también resulta reduccionista y vela las contradicciones internas que están produciendo los procesos de cambio material. En este sentido nos apartamos de una caracterización "comunitarista» del campesinado en oposición a grupos oligárquicos «privatizadores». Por el contrario, la ambigüedad y complejidad del proceso histórico y las transformaciones de la formación social en estos siglos, genera situaciones impuras, desde campesinos pobres que entran de noche fuera de los turnos permitidos a recolectar recursos de los montes y bosques violentando la normativa local, hasta grandes herederos que se valen de dicha normativa, reclamando la vigencia del carácter común de un término, para de ese modo obtener un acceso ventajoso a él ${ }^{23}$.

El comportamiento de las oligarquías urbanas excede el interés particular de sus miembros y se inscribe en una estrategia de la clase propietaria privilegiada. Las usurpaciones de grandes propietarios villanos responden a las nuevas formas

20. Monsalvo Antón, J. M., «Percepciones de los pecheros....», op. cit. Acerca de la no pasividad de los colectivos pecheros y de su notable plasticidad para formular estrategias sobre el problema de la propiedad común, hemos trabajado en LuchíA, C., «Propiedad comunal y lucha de clases en la Baja Edad Media Castellano-leonesa. Una aproximación a la dialéctica de la propiedad comunal», en Anales de Historia Antigua Medieval y Moderna, $\mathrm{n}^{\circ}$ 35-36, 2003.

21. Para un estudio de los líderes aldeanos, Astarita, C., «Representación política de los tributarios y lucha de clases en los concejos medievales de Castilla» en Studia Histórica (Medieval), vol 15, 1997.

22. «...por quanto algunos de los caballeros e escuderos e regidores e vecinos e moradores de la dicha çibdat traygan por exidos e devasos della sus ganados ovejunos e sus pastores traýan más ganado que ellos...», Ciudad Rodrigo, Doc 251, p. 292.

23. La propiedad común representaba «un importante respaldo económico para los campesinos, en especial para los menos favorecidos. No obstante, sufrió desde antiguo numerosos ataques por parte de la nobleza, de la Corona e incluso de los mismos vecinos, que intentaban ampliar o crear sus propias posesiones», López Benito, C., «Usurpaciones de bienes concejiles en Salamanca durante el reinado de los Reyes Católicos», en Studia Historica (Historia Moderna), vol. 1, nº 3, 1983, p. 169. 
de explotación que sin desligarse completamente de las viejas, sino en una cuidadosa articulación con ellas, comienzan a dar signos de la complejización de la estructura y organización productiva castellanas.

Nos referimos en particular al desarrollo de la ganadería trashumante y la producción de lana destinada al comercio de larga distancia, que reafirma el papel de estos grupos dentro de un subsistema de producción mercantil simple de mercancías ${ }^{24}$. La creciente ofensiva sobre los campos comunes que se registra desde el siglo XIV y con particular intensidad en el XV por parte de los sectores villanos, se corresponde en gran medida con la expansión de la actividad ganadera $^{25}$, cuyos rebaños presionan sobre las superficies comunes en detrimento de otras formas de explotación productiva de los suelos ${ }^{26}$.

La presencia de pastores es recurrente en la documentación, dando cuenta de la imbricación entre formas comunitarias consuetudinarias y vínculos salariales. Estos actores son utilizados frecuentemente por los «grandes y poderosos» del lugar para apropiarse de términos a los que no tenían acceso por su condición de extraños ${ }^{27}$. De este modo, los pastores, miembros activos de la aldea, son el instrumento de las estrategias acumuladoras de los sectores dominantes. Pero estas estrategias sólo pueden efectivizarse manipulando la pertenencia de los asalariados a la comunidad, con los cuales los caballeros y señores mantienen vínculos de dependencia y subordinación ${ }^{28}$.

La oposición entre los concejos cabecera y las aldeas que componen el término $^{29}$, por sus respectivos derechos de apropiación de los suelos públicos y $\operatorname{abiertos}^{30}$, no debe ser leída en tanto un simple conflicto jurisdiccional. Se trata de una pugna entre los núcleos urbanos que expresan el poder de las oligarquías de propietarios ganaderos y la masa de campesinos tributarios que conforman la

24. Para el concepto de régimen de producción simple de mercancías véase, Marx, K., Cap. XVIII, T. I, El Capital, Siglo XXI, México, 1994.

25. El conflicto entre la ganadería mesteña y las labranzas aldeanas es singularmente intenso en la Tierra de Soria por la presencia de un fuerte grupo de propietarios de ganado trashumante que mediatizan las relaciones entre las ciudades y las aldeas, Diago Hernando, M., Soria en la Baja Edad Media. Espacio rural y economía agraria, Ed. Complutense, Madrid, 1993.

26. Martín, J. L., «Evolución de los bienes concejiles...», op. cit.

27. Asocio, Doc 70, p. 172; Ciudad Rodrigo, Doc 251, p. 292.

28. «Gil Goncález... dixo este testigo que él, teniendo unas vacas suyas, que mandara a tomar a sus pastores en la sierra conçejil donde paçesen sus vacas, e aun que les mandara que lo que tomasen que fuese buen pedaço», Asocio, Doc 70, p. 172).

29. Véase entre otros, Asocio, Doc 76, 91.

30. Acerca de la cuestión, Diago Hernando, M., «Una institución de representación política del campesinado en la Castilla bajomedieval: Las Universidades de Tierra», en Historia, Instituciones, Documentos, 23, 1996. 
organización aldeana. El antagonismo de clases se traduce en una disputa por la autonomía de los concejos menores, muchos de los cuales obtienen de la Corona el reconocimiento de su segregación de las ciudades principales, accediendo a la condición de villa ${ }^{31}$.

La creación de pastos privados será el objetivo recurrente por el cual los grandes herederos acotarán dehesas en las aldeas a costa de sus términos comunes ${ }^{32}$. Sin embargo, la conflictividad no se reduce a una oposición entre usos productivos divergentes de villas prioritariamente ganaderas y aldeas principalmente agrícolas, sino revela un antagonismo estructural entre las bases campesinas de la Tierra y los intereses de los grandes propietarios. Si bien la obtención de pasturas para los grandes hatos de ganado es prioridad de los caballeros y señores locales $^{33}$, la complejidad de las formas de producción se expresa en la creación de explotaciones mixtas integrales que aseguran tanto el excedente comercializable como la renta agraria. La agricultura permite la subsistencia del campesinado y provee de bienes a los mercados locales, pero a la vez se integra dentro de una lógica de complementariedad entre dedicaciones y formas de apropiación del suelo productivo. La actividad agrícola de los aldeanos en sus parcelas individuales, tanto a censo como en condición de arrendamiento, exige el acceso a pastos para alimentar el ganado de labor. La reducción de las superficies comunes dificulta el mantenimiento de bueyes y animales de tiro así como de los animales domésticos de los tributarios más pobres. Estas circunstancias presionan a los semidesposeidos para emplearse como mano de obra de los grandes propietarios, quienes complementan la oferta del salario con el acceso a pastizales. Esto desata una competencia entre los miembros de las oligarquías por aventajarse en la obtención de trabajadores. Los sectores oligárquicos promueven una doble estrategia de compra y ocupaicón de heredades dispersas en la Tierra, como forma de garantizarse el derecho de usufructo de los comunes aldeanos, a la vez que realizan apropiaciones privadas de estos términos, ampliando la superficie disponible para pastos, tanto para su aprovechamiento directo, como para mejorar sus posibilidades de compra de fuerza de trabajo.

Como señala Monsalvo Antón en su estudio de Zapardiel de Serrezuela, aldea de la Tierra de Ávila, los herederos villanos «instrumentalizaron las tierras

31. «Y es mi merced que vos, el dicho lugar de La Adrada, que yo fago villa, ayades por termino e por cosa vuestra para vosotros todo el termino que vos aviades e de que hussavades a vos pertenesçia en cualquier manera seyendo aldea, con sus dehesas e montes e prados, aguas corrientes, estanques e con todas las cassas e poblados e alixares e vecinos e moradores que moran e moraren en todo el dicho termino», LuIS López, C., Documentación medieval de los archivos municipales de La Adrada, Candeleda, Higuera de las Dueñas y Sotillo de la Adrada, Institución Gran Duque de Alba, Ávila, 1993, p. 53.

32. Monsalvo Antón, J. M., El sistema político concejil, op. cit.

33. Barrios García, C. Estructuras..., op. cit. 
cerealistas para obtener pastizales y, con el concurso del factor mano de obra por medio, privatizaron pastizales para obtener renta agraria», en lo que constituye para el autor una integración dialéctica no dicotómica entre lo privado y lo comunal, entre agricultura y ganadería ${ }^{34}$. En este sentido, los intereses materiales que movilizan las conductas apropiadoras se inscriben en un plano más general dentro de las contradicciones de la singular dinámica transicional al capitalismo que se está abriendo en la región.

Los principales protagonistas de las usurpaciones se reiteran a lo largo de la sucesión incansable de pleitos, muchos de los cuales son continuidad de procesos anteriores cuyas sentencias nunca se efectivizaron por la acción coactiva de los grandes apropiadores o bien por su connivencia con los funcionarios judiciales ${ }^{35}$. Así lo evidencia la reacción del poder central en las Cortes de Zamora de 1432:

«muchas çibdades e villas e lugares de mis rengos e sennorios, que son demi corona rreal, estavan entrados e tomados muchos lugares e terminos e jurediçiones, por algunos perlados e caballeros e otras personas...la potencia de los tales sennores era tanta, que por ello o por el favor e ayuda que tenian en las tales çibdades...se quedavan con lo que ansi tomavan, e que por via de pleito non podian alcançar cumplimiento de justicia.... yo enbiare ala tal çibdad o villa o lugar buenas personas que sepan la verdad desto...provean e fagan conplimiento de justicia» ${ }^{36}$.

Las distintas modalidades de apropiación de tierras comunes constituyen una verdadera política de acumulación de patrimonios productivos de los grupos oligárquicos $^{37}$. Grandes propietarios urbanos que reiteradamente usurpan suelos co-

34. Monsalvo Antón, J. M., «Paisaje agrario...», p. 66, op. cit.

35. Frente a las tomas realizadas por los regidores, los vecinos de la Tierra acusan la complicidad y parcialidad que evidencian los jueces: «...todo avedes fecho e fazedes a favor e ayuda del dicho conçejo de Rrobreda e de algunos de los regidores desta çibdad, que se han apropiado e apropian otros devassos por sus bienes propios...», Ciudad Rodrigo, Doc 89, p. 154.

36. Cortes de León y Castilla, Real Academia de la Historia, T. IV., Madrid, 1882, pp. 127-128.

37. «(...) las dichas dos tierras, de suso deslindadas e declaradas, fueron e agora son del dicho Sancho Sánchez, mi parte, de los heredamientos que tiene en el dicho lugar Sant Pacual e en sus términos e sean poseydo e poseen por de mayorazgo, e an andado e andan anexos al mayorazgo del dicho lugar de Villanueva, arrendándolas e faziendo en ellas conmo en cosa suya propia, e en tal posysión pacífica vel casy ayan estado e están en él e los señores que an seydo de Sant Rroman e Villanueva por espacio de uno e dos e diez e veynte e treynta e quarenta e çinquenta e sesenta años a esta parte (...) arrendándolas e pagando rrenta por ellas a los mayordomos del dicho mi parte e de sus antecesores (...)», Asocio, Doc 186 p 764. «(...) después que los de Barrientos se apoderaron en el dicho lugar de Çapardiel et lo arrendaron a pan e a dineros de yerva, los que lo arrendaron rronpieron e araron las dichas quatro hojas e todo lo otro que estava por arar, e demás desto tyene arada la dehesa del conçejo de Çapardiel, por manera que este testigo non sabía deslindar qual es lo que conpró Pedro de Barrientos nin de quién, poque agora todo lo tyenen arado e rronpido los arrendadores de Pedro de Barrientos (...)»Idem, Doc 182, p. 709. 
lectivos son a su vez compradores de tierras dispersas en las aldeas del término ${ }^{38}$, conformando una base patrimonial amplia y diversificada que consolida su posición local. Este es el caso de los Pacheco, Osorio, Garcilópez, Cháves, Gómez de Herrera, Centeno y Águila en Ciudad Rodrigo; los diferentes troncos familiares de Ávila, con sus respectivos señoríos anexos, como los señores de Villatoro, Villafranca y Las Navas, Villanueva, Cespedoso y Puente del Congosto ${ }^{39}$.

Primero se controla una heredad propia en la aldea desde la cual se toman las tierras concejiles circundantes. Una vez que han logrado arraigarse en la localidad pueden emprender avanzar sobre los términos abiertos.

Señala un testigo:

«Lorenço Duran de Perosin, morador en Fituevo Dazaba...dixo que oyo decir que devasos avia y et que Estevan Yanes, desque cobro la Moheda, que juntara alguna tierra dello con lo suyo et Nuno Garçia, cavallero, que juntara con lo suyo de Mariín Ferrando de lo devaso del conçejo.... ${ }^{40}$

Este caso, es representativo de las numerosas acciones de este tipo que se registran en los concejos del área garantizadas por el poder y la fuerza:

Continúa: «Preguntado por que lo crey, dixo que porque lo oyo decir a ommes de verdat, e que segund ellos, avían el poderio que lo poiían muy bien fazer e pasar con ello... $\rangle^{41}$

La ocupación de los términos comunes desde posiciones de poder previas, tanto económica como política militar asume diversas formas. Junto a la entrada de términos y su cerramiento privado, adehesados a la heredad individual del caballero, encontramos otras formas de privatización de los comunales en las que interviene el empleo de la coacción a través de los dependientes de los poderosos. La toma de prendas por el aprovechamiento de espacios de uso libre y abierto es una constante en las demandas presentadas por los procuradores aldeanos:

«otro echo que dicen de los Foyos que tiene tomado Gil Gomez, señor de Villatoro et que lo tiene entrado e tomado Sancho Sánchez...oyó decir que

38. «El dicho Alfonso García Yzquierdo, vezino de Capardiel, testigo (...) dixo que (...) después los tienpos han venido tales, que los de Barrientos se apoderaron de este lugar, conprando de vezinos e herederos lo que aquí tenían, e que arrendaron este lugar de Capardiel a rrenteros, vezinos e de fuera (...)»en todos estos tienpos non sabe cosa propia de herederos nin de vezino, nin cree que ninguno sepa deslindar el heredamiento que aquí tyene Pedro de Barrientos, porque sus conpras fueron ciegas e non tienen deslindo ninguno, e ninguno ay oy de los bivos que sepa dezir quál es la heredad del que le vendió nin qué posnía quien ge lo vendió, conosçidamente, en las tierras de pan levar», Asocio, Doc 186, p. 762 y 763.

39. El papel dominante de estas familias en la vida concejil ha sido destacado por Monsalvo AnTón, J. M., «Percepciones políticas...», op. cit.

40. Ciudad Rodrigo, Doc 19, p. 41.

41. Idem. 
pastores e ommes suyos, del dicho Sancho Sanchez, que corrian los ganados de los vecinos de la dicho çibdat e de su tierra del dicho echo et los prendaban en el, et aun levaran prendados dende ciertos bueyes et levaran por ellos çinquenta maravedis» ${ }^{42}$

La coacción abierta aparece también mencionada, aunque sólo en muy pocos casos llega al empleo de la violencia extrema ${ }^{43}$. Esto significa que las acciones apropiadoras de los grandes herederos son cuidadosas de no afectar las fuerzas productivas entre las que se incluyen los productores directos ${ }^{44}$. La imagen que dan los testigos aldeanos de los grandes usurpadores es de «poderosos» que «contra razón y derecho» invaden, prendan, corren ganados, amenazan, dado el poder material que los grupos villanos han consolidado sobre la Tierra ${ }^{45}$. Entre las diferentes formas que adquiere la política de concentración patrimonial de las oligarquías urbanas, también hallamos tácticas legales, valiéndose de los propios procesos de cambio estructural que afectan a las comunidades campesinas, a la vez que inciden en ellos, agudizando sus contradicciones. Nos referimos particularmente a las compras de tierras al campesinado en situación crítica de endeudamiento tendientes a despoblar lugare ${ }^{46}$ para lograr la condición de principal heredero y cerrar su término con el concejil convirtiéndolo en término redondo ${ }^{47}$.

«(...) y el dicho Pedro de Avila avia provado bien e conplidamente el dicho Quintanar aver seido logar poblado e ser desmiero en la villa de Las Navas, villa del dicho Pedro de Avila, e avia provado asymismo que avía avido e conprado por justos e derechos titulos todos los heredamientos que eran e fueron en el dicho termino del Quintanar, el qual termino, segund la costunbre e hordenança nueva de la dicha çibdad usada e guardada, era e devia

42. Asocio, Doc 75, p. 296.

43. «(...) dixo que Alfonso Gonçález (...) guardava et prendava por los exidos que son en Tierra de Ávila et son conçegiles e son entre Manjaválago et Gamonal (...) et aunque a su padre levaron omnes de Alfonso Goncález preso a Ortigosa et el tovieron una noche preso et enaspado (...)», Asocio, Doc 72 p. 196.

44. «...porque non querýan los que alli moravan obedecer a Avila et a los caballeros della, que venieran al dicho lugar et lo quemaron et lo destruyeron...», Asocio, Doc 76, p. 331.

45. «...vido que quando lo fue a tomar que levó consigo pieça de omes e que fizo echar la rraya con bueys por donde se guardase e que con miedo non ge lo osaron contradezir persona alguna...dixo que se los tomara porque era poderoso e que los labradores de la comarca con miedo que non osaron demandarlo...», Asocio, Tomo I, Doc 74, p. 260.

46. «...Pedro de Barrientos tyene a media legua de Çapardiel un lugar suyo que se dize de Serranos de la Torre a él se ha trabajado por acrecentar el dicho lugar Serranos e le aprovechar con los términos del dicho lugar Çapardiel, e ha procurado de despoblar el dicho lugar Çapardiel...», Asocio, Doc 186, p. 745.

47. La conversión en término redondo, ha sido un fenómeno importante en algunas ciudades, aunque sólo podían aspirar a ello, los sectores más concentrados de la elite, dejando en el camino a los propietarios menos cuantiosos. El tema ha sido estudiado pro Monsalvo AnTón, J. M., en «Paisaje Agrario», op. cit. 
ser termino redondo, pues que en el non se provava nin paresçia aver otro heredero alguno salvo el dicho Pedro de Avila» ${ }^{48}$.

Pese a la coincidencia de los miembros de las oligarquías locales en acciones usurpatorias comunes, su lógica competitiva, sólo suspendida en momentos puntuales de amenaza a la reproducción del vínculo de dominación sobre el campesinado, favorece peligrosamente la individuación de los sectores de poder ${ }^{49}$. Los enfrentamientos entre los grandes locales se manifiestan en las mutuas incriminaciones que se formulan en los litigios. La acusación a otros caballeros, si bien puede justificar la conducta propia, como es el caso reiterado de caballeros que declaran «usurpar porque otros usurpan ${ }^{50}$, exhibe el vínculo competitivo y contradictorio que los une. Esta situación se aprecia en la habitual impugnación de testigos, observándose que muchas declaraciones están orientadas a la obtención de tierras a costa del acusado. Generalmente los testigos que generan esta contraofensiva por parte de los procuradores del «usurpador», pertenecen a su misma clase $\mathrm{e}^{51}$. De este modo es pertinente pensar que las luchas por los comunes no encuentran a una fuerza social dominante unida sino que por el contrario activan la dinámica competitiva que le es inherente ${ }^{52}$. Las rivalidades dentro de las oligarquías locales en pleno proceso de acumulación territorial a expensas de

48. Asocio, Doc. 192, p. 788 y 789 ;

49. Se advierte en ciertos pleitos extensos de Ávila, la naturaleza fragmentada y competitiva del poder feudal. Véase Asocio, Doc 70, p. 168 y Doc 74, p. 228. Se observa la compleja trama de estrategias mediante las cuales los competidores se enfrentan, involucrando a los demás actores de la comunidad: descalificación de testigos, denuncia de la acción violatoria del rival, manipulación de los elementos subordinados de la aldea para testificar en contra del oponente, como es el caso de los pastores, son algunas de estas prácticas.

50. «(...) respondiera al dicho Conde que era verdat que él, veyendo que algunos de los caballeros e escuderos de la dicha cibdat que tenían entrado e tomado gran parte de las dichas syerras e que los dichos omnes buenos non reclamaban, e que este testigo que avía tomado el dicho echo (...)», Asocio, Doc 70, p. 172. Aquí observamos como la dinámica competitiva que instalada en el interior de la clase de poder actúa como justificación de la acción individual, a la vez que la no defensa del comunal en el pasado por los aldeanos, crea derechos, para el que lo ocupa efectivamente. «(...) lo quería apropiar para sy, et que esto lo fazía porque otros avían tomado asaz de tierra de Avila et que quería él tomar su parte, et que, sy reclamasen sobrello, que todos los otros que dexasen lo que avían tomado et que él que lo dexaría (...)»Idem, Doc 71, p. 195.

51. «(...) Pieres Guiera, caballero,....dixo este testigo... que Gil Gonçález, fijo de Estevan Domingo, que de quatro o çinco años a esta parte que avía tomado pieça de una sierra conçejil...e que prendava a los veçinos de Ávila (...)», Asocio, Doc 70, p. 176.

52. El propio acusado descalifica como testigo a Alfonso Goçález, miembro del conçejo y a su vez acusado por toma de tierras en otro pleito: «El dicho Alfonso Gonçález non me empeçé por lo susodicho e porquer es omne que me ha odio capital e me quiere mal de muerte et porníe el cuerpo e la ánima por me fazer mal e daño, así en mi onrra conmo en mi fazienda e estado; (...) et era al dicho tiempo e es mi contrario conocido e tenía tregua conmigo por razón de la gran inimistancia que entre él e mí era al dicho tiempo e antes (...)». «(...) et contra los otros testigos por vos en en este proceso rrecebidos, que ellos e cada uno dellos non pueden nin podieron contra mí testificar en esta cabsa por quanto parecen testificar en su cosa propia, pues que a cada uno dellos singularmente le venía provecho, sy me vencieran en esta cabsa, ça parecerian con 
los términos colectivos, actúa a su vez como un freno a la absoluta señorialización del espacio ${ }^{53}$. Las dificultades para imponer sin contestación atribuciones señoriales, no resultan sólo de la resistencia de las comunidades y la reacción del poder central, sino de las propias disputas entre sus integrantes.

Competencias y solidaridades internas, disputas por tierras, mano de obra y posiciones dentro del aparato concejil, complejo y ambivalente vínculo con los funcionarios reales, son algunos de los elementos que condicionan la estructuración de las redes de poder local de los sectores dominantes. Su posición como fuertes propietarios de ganado, se ve favorecida por su ubicación en los principales cargos políticos locales desde los cuales refuerzan su ofensiva sobre la propiedad comunitaria ${ }^{54}$. El caso de los Regidores abulenses es indicativo del papel que cumplen las superestructuras institucionales en la consolidación de las redes de poder, ya que desde sus posiciones de supremacía política, pueden elaborar ambiciosas estrategias patrimoniales y promover una dinámica expansiva de sus actividades productivas ${ }^{55}$. Gil González y Diego González del Águila son dos de los doce regidores de la ciudad, que aparecen recurrentemente acusados de apropiación de comunales aldeanos. Pero sus acciones no son coyunturales sino que se inscriben en una lógica familiar intergeneracional que tiende a reforzar y acrecentar los patrimonios adquiridos ${ }^{56}$. El padre de Gil González, Esteban Domingo, es un gran usurpador cuya constante presencia en los pleitos señala la continuidad secular de esta política ${ }^{57}$.

El siguiente cuadro ejemplifica sintéticamente, la presencia de los propietarios más comprometidos en los dos procesos judiciales más extensos seguidos en Ávila en el siglo xv. El primero entre 1415 y 1416 y el segundo luego de la sanción de las Leyes de Toledo y la fuerte intervención monárquica para recuperar el patrimonio comunal erosionado, entre 1490-1493. En el mismo puede

sus ganados los dichos echos e tierras e sierras e términos que yo poseo et dicen a la dicha çibdat pertenecer (...)», Asocio, Doc 75, p. 302. y 303.

53. Astarita, C., «Estructura social del concejo...», op. cit.

54. «...la potencia de los tales señores hera tal que por ello e por favor e ayuda que tenían en las tales çibdades e villas e lugares se quedavan con lo que ansý tomavan, e que por vía de pleyto non podían alcançar conplimiento de derecho...», Ciudad Rodrigo, Doc 164, p. 240.

55. El acceso al Regimiento es una aspiración permanente de las principales familias, a partir del proceso de oligarquización que bajo el reinado de Alfonso XI consolida la instauración del regimiento, tendiendo a conformar linajes que patrimonializan los oficios públicos superiores, VALDEÓN, J., «Las oligarquías urbanas», op. cit.

56. Igual política patrimonial se verifica en el caso de Pedro de Ávila: «...por los desórdenes destos nuestros rreynos e por el poder e mano e mando que en la dicha çibdad de Ávila el dicho Pedro de Ávila e los de su casa avían tenido en la dicha çibdad e en regimiento della, syenpre de fecho avían tomado e ocupado...de la dicha çibdad de Avila e de sus terminos muchas partes...», Asocio, Doc 193, p. 818.

57. Asocio, Doc 74, pp. 223 y ss. 
apreciarse la trama familiar que vincula las tomas individuales dentro de una política más amplia, así como el alcance regional que tiene la misma, como lo indica la presencia de propietarios segovianos involucrados en apropiaciones en el término de Ávila:

\begin{tabular}{|l|l|}
\hline Sancho Sánchez & Hijo de Juan Velásquez, Señor de Villanueva \\
\hline Gil González & Hijo de Esteban Domingo \\
\hline Alfonso González & Hijo de Esteban Domingo \\
\hline Toribio Ferrández & Hijo de Esteban Domingo \\
\hline Diego & Hijo de Pero González de Águila \\
\hline Pero González de Ávila & Oidor del Rey \\
\hline Gil Gómez & Señor de Villatoro y Navalmorcuende \\
\hline Alfonso González Gil González & Regidores abulenses \\
\hline Sancho Sánchez de Ávila & $\begin{array}{l}\text { Hijo de Gómez de Ávila Nieto de Sancho Sánchez el Bermejo, padre } \\
\text { de Gonzalo de Ávila. }\end{array}$ \\
\hline Diego González & Hijo de Pero González de Contrera. Vecino de Segovia \\
\hline Diego González del Águila & Hijo de Nuño González. Regidor abulense \\
\hline
\end{tabular}

Las vinculaciones con el poder político concejil, por un lado, y con los funcionarios reales, por otro son rasgos generales de los grupos dominantes villanos; de allí que las redes de poder se conforman en el entrecruzamiento de elementos patrimoniales basados en la fortaleza de los lazos familiares, el control de los resortes políticos locales y la relación con los funcionarios regios.

Las necesidades inmediatas e individuales de los miembros de la elite que impulsan la ofensiva privatizadora, lleva a poner en riesgo la lógica clasista de reproducción de los sectores dominantes amenazando sus intereses estratégicos, en tanto la búsqueda de ventajosas condiciones de acumulación patrimonial refuerza tendencias centrífugas que liberan una competitividad que debe ser frenada por las instancias superiores de poder. Es en esta tensión que los concejos como expresión política mediadora entre el interés individual y el interés estratégico, deben intervenir para preservar las formas de producción que aseguren la reproducción de la totalidad. Si bien es habitual que oficiales menores del concejo entorpezcan la acción de la justicia en beneficio de la oligarquía, de cuyo favor reciben los cargos, en especial apelando a la argucia de dilatar los pleitos $^{58}$, la preservación de la lógica material debe trascender las necesidades

58. López Bentto, C., «Usurpaciones de bienes...», op. cit. 
de la coyuntura. Así es como los concejos en muchas ocasiones se ven constreñidos a preservar el patrimonio colectivo de la rapacidad de algunos de sus miembros más destacados. Sin embargo, en muchas circunstancias las urgencias financieras y las necesidades de financiamiento del aparato concejil, también inciden en las acciones lesivas contra el patrimonio comunal, como se aprecia en la conversión de comunes en propios $^{59}$, con que los concejos cabeceras logran obtener renta de la explotación de las antiguas tierras abiertas. En este proceso, la apariencia de continuidad del carácter común encubre la instauración bajo la forma del arrendamiento de una relación de explotación nueva que somete a la población aldeana a nuevas exacciones ${ }^{60}$.

\section{PODERES LOCALES Y MONARQUÍA}

Si bien la regulación de estos campos y la organización económica de sus usos despertó el interés temprano de la Corona ${ }^{61}$, los períodos de cambio de coyuntura (ya sea de expansión o de retracción) al intensificar las luchas por su disfrute exigen intervenciones ordenadoras ${ }^{62}$.

Las disposiciones del poder central en torno a la cuestión adquieren singular importancia a partir de las Cortes de Toledo, en las cuales la Corona, ante las crecientes demandas de los representantes concejiles promueve una política activa que a la vez que intenta paliar la continua merma de estos espacios a manos de las oligarquías ciudadanas y las fuerzas señoriales, pretende recuperar la capaci-

59. Marcos Martín, A., «Estructura de la propiedad en la época moderna: Evolución y variantes peninsulares», en De Dios, S., Infante, J., Robledo, R., Torrijano, E., (Coords) Historia de la propiedad en España s. $X V-X X$, Encuentro Interdisciplinar, Salamanca, 3-6, junio 1998.

60. La pérdida del carácter realengo de muchos términos durante el reinado de Fernando e Isabel, es producto de muchas concesiones dadas a los concejos para la labranza de las tierras proveyendo de rentas de propios a las ciudades, se trata por tanto de una forma de privatización limitada, Diago Hernando, M., 1993, op. cit.

61. Véase para ello desde las regulaciones establecidas en los Fueros hasta las concesiones otorgadas por los soberanos como es el caso de la efectuada en 1176 por Alfonso VIII al concejo de Madrid con la usual fórmula «dono et concedo montes, pinares, pasqua, prata, extremos populator et eremos, totos ex integro», en González, J., El reino de Castilla en la época de Alfonso VIII, T. II, doc 242, Madrid, CSIC, 1960. Su definición doctrinaria se precisa en las Siete Partidas: «son establecidos e otorgados para procomunal de cada çibdad o villa o castillo o lugar. Ça todo omme que fuere y morador puede usar de todas estas cosas sobredichas: e son comunales a todos, tambien a los pobres como a los ricos. Mas los que fuesen moradores en otro lugar non pueden usar de ellas contra voluntad o defendimiento de los que morasen y».

62. Al respecto señala Monsalvo AnTón, J. M., «Así, para el siglo XIv es fácil achacar el fenómeno de las usurpaciones y las conductas apropiadoras y abusivas de los grandes a la crisis general de ese siglo. Es posible, pero resulta que en el siglo xv, en una fase que se considera expansiva, el fenómeno de las usurpaciones adquirió un despliegue enorme, y entonces la superación de la crisis, que parece innegable, puede explicar las mismas cosas que explicaba ésta...resultaría así que los poderosos usurpaban cuando la economía iba mal y también cuando iba bien», «Paisaje agrario...». op. cit. 
dad imperativa debilitada por las tendencias señorializadoras que se registran en varios concejos.

Así describen las Leyes de Toledo la situación de apropiación y despojo de la que es objeto el patrimonio comunal concejil:

«a los pueblos se les recrecen dos dannos, uno es la toma e ocupacion de sus terminos, e lo otro es las costas valdias que fazen para los recobrar e porque somos informados que muchas çibdades e villas e logares de nuestros rreynos, especialmente de nuestra corona real, estan muy desapropiados e despojados delos dichos sus lugares e jurisdicciones e terminos e prados e pastos e abrevaderos» ${ }^{63}$.

Por consiguiente, la autoridad central pretende poner freno a los abusos promovidos por las fuerzas locales, restituyendo las tierras usurpadas y restaurando el imperio del realengo en los concejos en los cuales las oligarquías villanas y los linajes nobles han avanzado sobre la jurisdicción real:

«...e commo quier que tienen sobreello sentencias, no pueden alcanzar la execuçion dellas...mandamos que...por el mismo fecho el tal ocupador que fiziere resistencia contra la dicha sentencia o mandamiento o fuere contra ella, pierda e aya perdido qual quier derecho que toviere e pretendiere aver, si lo toviere, al sennorio e propiedad de la cosa... e que pierdan los oficios que toviere, así de nos como de qualquier cibdades, villas e logares, e si no tuviere officio que pierda el tercio de sus bienes para la nuestra camara... ${ }^{64}$

Sin embargo, pese a esta nueva disposición «proteccionista» del poder central, la compleja estructuración de la dominación feudal en cada concejo obliga a observar con detenimiento las condiciones específicas que explican en algunos casos la firme aplicación de estas políticas o por el contrario, la reafirmación de los intereses de los grandes apropiadores. La monarquía pese a establecer un principio general de resguardo de los términos comunes debe dialogar permanentemente con las redes de poder conformadas en cada lugar.

Las presiones ejercidas sobre la población pechera tendientes a despoblar lugares es una de las quejas más intensas que los campesinos elevan a la Corona, enlazando sus intereses con la defensa del realengo, en tanto el vaciamiento de lugares importa una pérdida de tributarios para la monarquía, argumento esgrimido reiteradamente por los representantes aldeanos ${ }^{65}$.

63. Pet. 82, Idem, p. 155.

64. Ibidem. p. 156.

65. Son numerosos los documentos en los que se presenta la acusación contra los usurpadores en términos de la mengua de los intereses fiscales de la monarquía., «(...) nos, el conçejo de Ávila, ayuntados en la eglesia 
El desconocimiento de las sentencias regias, la violencia abierta ejercida contra los jueces enviados por el monarca a ejecutarlas, la impugnación constante de las actuaciones judiciales, dan cuenta de la compleja situación que debe enfrentar la monarquía para hacer efectiva su potestad jurisdiccional en el ámbito concejil de realengo ${ }^{66}$.

Como ya hemos señalado, la relación ambigua que los sectores dominantes concejiles establecen con el poder superior del rey, se caracteriza por un dualismo entre la cooperación, en tanto aseguran la reproducción del señorío regio como transmisores de la renta feudal centralizada y eficaces organizadores de la producción a través del aparato concejil que controlan, y la competencia, cuando los grupos más poderosos logran desarrollar enclaves señoriales. En estos casos, la señorialización del espacio implica una disputa con la jurisdicción realenga que no sólo se expresa en la caída de rentas sino en un debilitamiento de su potestad imperativa:

«...los que bebian en el dicho logar de las Fuentes que davan cosa çierta a Diego Alfonso e Johan Gonçalez e despues a Martin Lopez e agora a Lope Ferrandez de lo que labravan e cogian...porque los defendian de la martiniegas e de las soldadas de los Juyzes e de los fuegos e de los otros tributos que venian.... ${ }^{67}$

Así puede apreciarse también en las demandas elevadas por la apropiación de comunes por el obispo de Segovia:

«...han fecho e fizieron infiutosamente donaciones e traspasamientos de los dichos terminos, prados e montes e dehesas e pinares a algunas personas eclesiásticas, a fin e con entinçion de que non sean tenudos nin obligados a rresponder nin parecer ante vos sobrello... $\rangle^{68}$

de Sanct Juan a canpana rrepicada, ansí conmo en nuestro uso e nuestra costunbre, (...) veyendo que se hermanavan las aldeas del pueblo de Avila, por que se yvan a Oropesa e a Çervera et a otros lugares que non es serviçio del rrey, et esto que era en su deserviçio e que non fincavan y pecheros que pechasen los sus pechos (...)», Asocio, Doc 24, p. 71. Véase también Ciudad Rodrigo, Doc 20, p. 51.

66. «Domingo Sanchez.., testigo (...) dixo, (...) que sabía que Nuño Goncalez del Aguila (...) e que por fuerça e contra razon que tomo muchas tierras de las comunes e conçegiles de aderredor de la dicha su tierra (...) dixo que las tomó por fuerça e contra razon (...) que quando las fue a tomar que levo consigo pieça de omnes e que fizo echar la raya con buey por donde se guardase e que con miedo non ge lo osaran contradezir persona alguna (...)», Doc 74, p. 258. «(...) E yo, Andres Gonçalez, escrivano publico de los rreyes (...) vi conmo el dicho Bernaldino tomo una vara que llevava Pero Gomez, alcalde en Çapardiel, que ge la iva a notyficar (...) e ge la tomo de la mano forçosamente e ge la fizo pedaços en la cabeça e le dixo a el e a los otros que con el yvan que les faria comer la carta e los ahorcari, que non dexaria ninguno, que non tenían alli que entender el rrey nin la rreyna, salvo el (...)», Asocio, Doc 183, p. 735. Se trata en este caso de uno de los hijos del poderoso caballero usurpador Pedro de Barrientos.

67. Ciudad Rodrigo, Doc 19, p. 45.

68. Asocio, Tomo I, Doc 106, julio 1434, p. 443. 
La defensa formal del realengo, del orden legal, de los bienes públicos y baldíos expresan un progreso estructural de la centralización monárquica que se impulsa durante la dinastía Trastámara, aunque sus efectos concretos están siempre sometidos a contestación por los poderes locales ${ }^{69}$, así como por las propias oscilaciones políticas del poder central.

La mayoría de las sentencias que favorecen la restitución a las comunidades del usufructo libre de sus términos ${ }^{70}$, desafían a los grandes apropiadores procedentes de la nobleza, la caballería villana y las corporaciones eclesiásticas, en especial a los integrantes de la organización concejil ${ }^{71}$. Con estos fallos se pretende asegurar el equilibrio socioproductivo local, para lo cual la disponibilidad de la tierra comunal constituye un complemento necesario de la subsistencia campesina $^{72}$, a la vez que proteger los propios intereses monárquicos en cuanto se preserva la reproducción de sus pecheros ${ }^{73}$. La Corona defiende su base tributaria haciendo lugar al reclamo aldeano ${ }^{74}$. Sin embargo en otros casos, favorece las apropiaciones y legitima el traspaso de jurisdicción concediendo ella misma potestades señoriales. Mientras que la amenaza a la plena vigencia de la juris-

69. Monsalvo Antón, J. M., «Usurpaciones de comunales...», op. cit.

70. «...visto el proçeso de dicho pleito...e la dicha sentencia e ordenamiento del dicho rey, nuestro padre, que por parte de los dichos pecheros fue presentada...e los dichos de los testigos...dieron sentencia...en que fallaron que, asi por las provanças traydas ....por el procurador de los dichos pueblos e pecheros de Avila...se probaba asaz quanto conplia de derecho que el dicho echón que dicen de Pennalbueytre...que eran terminos e pinares de la dicha çibdat de Avila e pastos conçejales e comunales de la dicha çibdat e de los caballeros e escuderos e pecheros della e de sus terminos», San Bartolomé de Pinares, Doc, 15, p. 42.

71. La presencia de estos poderosos locales entre los apropiadores más destacados es reconocida entre otros, por Fortea Pérez, J. I., «La propiedad de las corporaciones urbanas», en De Dios, S., InFAnTe, J., RoBledo, R., Torrijano, E., (Coords), Historia de la propiedad en España. Siglos XV-XX. Encuentro interdisciplinar, Salamanca, 3-6, junio, 1998; CARmona RuIz, M. A., La ganadería en el Reino de Segovia durante la Baja Edad Media, Sevilla, 1998; Mangas Navas, J., El régimen comunal agrario de los concejos de Castilla, Servicio de Publicaciones Agrarias, Madrid, 1981; Monsalvo Antón, J. M., op. cit., 1992.

72. Los pecheros de Trujillo piden al enviado del monarca Juan I para que entiende en cuestión de pleitos por los comunes que desacote un berrocal para su uso agrícola, las razones que aluden serán tenidas en cuenta por el juez en tanto la privatización del comunal obstaculiza la reproducción campesina: «...vos denunciamos e fazemos saber que el berrocal de aquí de Trujillo de en derredor de la villa...que es exido comunal del dicho conçejo para lavor de pan e para pasto e leña e aguas e caça para todos los vecinos e moradores desta villa, asy caballeros e escuderos e pobladores e seyendo exido comunal para todos en comunalmente, algunos de los que an de ver fazienda del conçejo desta dicha villa pusieron e ponen enbargo en la lavor del dicho berrocal, por el qual enbargo nosotros e otros muchos omes e mugeres menesterosos que non avemos heredades de nuestro...viene de cada dia muy grant daño a todos los sobredichos por quanto el dicho berrocal es muy provechoso para esta villa quando se labra», SÁnchez RuBio, M. A., Documentación medieval del Archivo municipal de Trujillo (1256-1516), Parte I, Institución Cultural El Brocense, Cáceres, 1992, Doc 46, p. 57.

73. Alfonso XI reconoce la situación «...quela mi tierra es rrobada e astragada e yrema elas rentas son menguadas...», Cortes, Tomo I, Cortes de Valladolid de 1325, Pet. 1, p. 373.

74. Ciudad Rodrigo, Doc 20; Asocio, Doc, entre otros. 
dicción real, en algunas circunstancias y dependiendo del balance efectivo de fuerzas en el nivel local, es enfrentada, en otras es favorecida, cuando los intereses estratégicos del poder central se ven beneficiados por una alianza con los sectores dominantes locales promovidos a condición señorial.

El reclamo de Ciudad Rodrigo ante el rey Juan II por la concesión realizada a Fernand Nieto, uno de los grandes locales, es respondido con la confirmación de dichos privilegios en los términos siguientes:

«...Yo fize merced para siempre jamas a Fernand Nieto, mi vasallo e guarda de la juridiçion et justicia çevil e criminal...mande dar e di al dicho Ferrand Nieto, e lo guardedes e cunplades e fagades guardar e conplir en todo e por todo...le dexedes e consintades usar de lenna dicha justicia e juridiçion e poner e tener las dichas forcas... $\gg^{75}$.

En sentido contrario a esta disposición, en el extenso pleito seguido en 1490 contra Pedro de Barrientos por el término abulense de Zapardiel, la actitud regia es protectora del realengo. Al mismo tiempo que concede casas y solares a campesinos para evitar el despoblamiento, impide expresamente toda posibilidad de avecindamiento por parte de grandes propietarios foráneos:

«....mando dar con condicion que la casa o casas que en los dichos solares se fiziesen por venta nin por manda nin por donacion... nin a monesterio nin a dueña nin a doncella nin a caballero nin a escudero nin a omme poderoso, salvo pechero e fijo de pechero que fuese en los pueblos e tierra de la dicha çibdad...» ${ }^{76}$

La intervención monárquica no sólo resguarda las bases materiales de reproducción campesina sino que configura el entramado institucional del reino. Al subordinar a los concejos al vértice superior les reconoce un poder que será fuente de numerosos conflictos. Los concejos están autorizados para prendar a quienes invadan sus términos, confirmando una práctica evidentemente previa y delegando en los poderes locales, el cuidado y regulación de suelos que con carácter eminente le pertenecen a la Corona ${ }^{77}$. La autoridad conferida a los gobiernos locales reforzará aún más las tendencias a la concentración hereditaria en el mismo grupo de las funciones concejiles, refrendadas por la legitimación del poder superior.

75. Ciudad Rodrigo, Doc 282, p. 319.

76. Asocio, Doc 186, p. 747.

77. «Si ganado de otra uila en termino de Plazencia o en sus terminos o estremos a pacer entrare, el conceio quintelo sin calonna et despues saquelo de sus terminos et este quinto (to) menlo de oueias et de vacas et de puercos et de yeguas et de todo ganado», Idem. La figura del guarda o montaraz será de vital importancia en la custodia de estos bienes. 
La política de la monarquía no puede definirse en un plano abstracto general en términos de un «espíritu proteccionista»o «privatista», de allí que resulte por momentos ambivalente, en tanto no responde a una orientación uniforme y de alcance general para el reino, sino que se adapta creativamente a la relación que establece el poder central con cada concejo en particular y con sus respectivos grupos dominantes. Las decisiones tomadas en uno y otro sentido sólo cobran coherencia si se las estudia en su existencia práctica.

¿Qué motiva estas oscilaciones en la política monárquica? La respuesta no puede encontrarse ni en la materialización de un programa como el pretendido por los arbitristas a partir del siglo XVI, ni en las constricciones de la coyuntura financiera o demográfica. Sólo remitiéndonos a la dialéctica de la totalidad es posible alcanzar un grado de comprensión de las impurezas y ambigüedades del fenómeno estudiado. Por ello pensamos las políticas en torno a la propiedad comunal desde una perspectiva amplia de las relaciones de poder en la región, desde el diálogo permanente entre las fuerzas locales y los soberanos.

Tanto la política de la Corona como la de las oligarquías concejiles no se encuentra mecánicamente prefijada. Sin embargo, la variedad de disposiciones no es errática; por el contrario se halla determinada por la relación efectiva de fuerzas sociales y económicas. En ciertos momentos se impone la lógica «feudal», en otros la lógica «tributaria» o bien la lógica política del poder superior que debe preservar la base material de las elites concejiles. Este es el sustrato que explica la coexistencia de racionalidades superpuestas y aparentemente contradictorias.

\section{A MODO DE CONCLUSIONES PROVISORIAS}

La concentración de propiedades y el acaparamiento de los principales cargos del aparato político concejil por los grandes propietarios señalan la confluencia de un doble proceso de consolidación como sector dominante. Desde una base de poder económico previo se lanzan a conquistar el poder político desde el cual potenciarán el proceso de acumulación y enriquecimiento.

Sin embargo, como hemos advertido ya, estas redes de poder local que se traban en las distinta ciudades del realengo distan de ser agrupamientos armoniosos. La propia lógica de atomización que estructura el feudalismo como régimen de producción alcanza a las oligarquías villanas. Los intentos de señorialización que parten de sus miembros más poderosos son producto de una dinámica material que tiende a la descomposición del poder y a la singularización de la propiedad, a la vez que enfrentan las tendencias hacia la concentración que se despliegan a finales de la Edad Media. Esta dialéctica del desarrollo histórico, expresado en la pugna entre particularización vs centralización del poder tanto material como político, se aprecia en aspectos concretos como la regulación de 
la vida económica local. Si bien muchas de estas cuestiones son abordadas por los ordenamientos de cada concejo ${ }^{78}$, las resoluciones del poder central actúan como fuente generadora de derecho o bien como instancia de legitimación de las normativas municipales, muchas de las cuales precisan el contenido de los fueros originarios ${ }^{79}$. La confirmación de privilegios ${ }^{80}$, por un lado, y por otro, casos como los señalados, en los cuales la autoridad del soberano no alcanza para efectivizar las sentencias ${ }^{81}$, dan cuenta de la lucha entre estas dos tendencias que vertebran la construcción política feudal.

La dinámica del feudalismo se expresa en la disputa entre los esfuerzos centralizadores de un estado monárquico que intenta imponer su supremacía y poderes que pugnan por su autonomía relativa ${ }^{82}$. De allí la constante tensión entre los soberanos y los concejos, las oligarquías villanas, las instituciones eclesiásticas e incluso los propios funcionarios regios que terminan apropiándose de potestades de origen público ${ }^{83}$. Tensión que si bien se manifiesta en un plano superestructural, emana en última instancia de la morfología del feudalismo castellano.

78. Ladero Quesada, M. A.; Galán Parra, I., «Las ordenanzas locales en la Corona de Castilla como fuente histórica y tema de investigación (siglos XIII al XVIII)», en Anales de la Universidad de Alicante. Historia Medieval, Alicante, 1982.

79. Carmona Ruiz, M. A., «La organización de la actividad ganadera en los concejos del reino de Sevilla a través de las ordenanzas municipales», en Historia. Instituciones. Documentos, 25, 1998.

80. En Carta del rey Enrique IV a la ciudad de Trujillo se observa la adecuación de la normativa general a las condiciones particulares de cada concejo y a la posición específica que éste ocupe dentro del entramado político y económico general del reino: «Sepades en conmo yo e de aver en cada un año serviçio e montadgo de los ganados de los mis reynos que entran a los estremos e salen dellos e otrosy de los ganados que fueren fuera de sus terminos a vender en las ferias e en los mercados...que non levaren alcabala...que paguen serviçio dellos...delos ganados que fueren fuera de las villas e logares donde moraren e de sus terminos e non obieren serviciado...el qual dicho serviçio e montadgo fue mi merced de mandar arrendar por seys años», Quaderno de leyes del serviçio montadgo, Sánchez Rubio, M. A., Documentación Medieval. Archivo Municipal de Trujillo, Parte III, Ordenanzas Municipales 1415-1517, 1995, pp.110-111.

81. «...e porque ya sobre este mismo termino avia seido litigado ante juez competente entre los dichos sus partes...e avina seido dadas sentencias por las quales el dicho termino del Quintanar avia seido mandado restituir e entregar a la dicha çibdad e su tierra e pueblos...», Asocio, Tomo II, Doc 192.

82. La defensa formal del realengo, del orden legal, de los bienes públicos y baldíos expresan un progreso estructural de la centralización monárquica que se impulsa durante la dinastía Trastámara, aunque sus efectos concretos están siempre sometidos a contestación por los poderes locales, Monsalvo AnTón, J. M., «Usurpaciones de comunales...», op. cit.

83. La concordia celebrada entre Ciudad Rodrigo y el concejo señorializado de Fuenteaguinaldo en 1432 muestra la debilidad de la preeminencia de la potestad regia: «...e para cada cosa e parte dello asi thener, guardar y cumplir, e pazer, ambas las dichas partes e cada una dellas por si dixeron que davan e dieron todo su poder cumplido a qualquier juez e justicia o alcalde o alguacil o merino o portero o ballestero o otra qualquier justicia, ansi eclesiastica commo çevil, asi de la corte del dicho señor rey como de qualquier çibdad, villar (SIC) o lugar que sea...», Ciudad Rodrigo, Doc 156, p. 231. 